\title{
The Research on Price Strategy to Incent China's Drug Innovation
}

\author{
Bin Zhou ${ }^{1} \&$ Xiaoming $\mathrm{Wu}^{1}$ \\ ${ }^{1}$ China Pharmaceutical University, Nanjing, China \\ Correspondence: Xiaoming $\mathrm{Wu}$, China Pharmaceutical University, Nanjing 210009, China. E-mail: \\ xmwu@cpu.edu.cn
}

Received: December 29, 2014 Accepted: April 6, 2015 Online Published: April 27, 2015

doi:10.5539/par.v4n1p78

URL: http://dx.doi.org/10.5539/par.v4n1p78

\begin{abstract}
In the past few years, there has been a rapid development in China's generic drug market, while the new drug innovation performance is not outstanding. As an effective means to achieve multiple policies for the government, drug price not only maintains the new health reform target of drug accessibility and lower drug costs, but also plays a crucial role in drug innovation incentives. Through the analysis of current situation of Chinese medicine manufacturing drug innovation and existing problems, the authors discussed the role of drug price incentive compensation mechanism in innovation, and proposed the following price incentive strategy, using the pharmacoeconomics evaluation system, into the compensation directory, setting up the mechanism of drug price negotiations and by means of controlling medical costs.
\end{abstract}

Keywords: drug innovation, drug pricing, incentives, drug compensation

With the advancement of China's medical and health system reform and the trend of population aging, there has been a rapid development in China's health care and medical industry. In China, the rapid development of generic drugs makes performance of the new drug research and development be outshone. As the main ways and means to maximize the interests for companies, drug price is not only a focal point of drug innovation incentive policy, but also an important focus of patients, medical service institutions, medical insurance institutions, government and other stakeholders. There are multiple policy objectives which are self-contradictory in the administration of drug price regulation. For example, in the process of motivating new drug research and development, supporting the development of pharmaceutical industry, the government should also achieve the targets, such as maintaining the accessibility of innovative drugs for patients, reducing drug costs, reducing the pressure of medical insurance fund and promoting the rational use of drugs and other targets. The government transfer the pressure of medical system reform to drug consumption because of the difficulty in pushing the China's medical and health reform process, through the policies of reducing price many times and zero rate of basic drugs, the government makes up for the inadequacy of paying for the medical and health care. The ideal innovative drug price management mechanism should be able to combine the sustainable development benefits and incentives with the sustainability of social resources input in medical field, the consumers' health welfare and social justice.

\section{The Current Situation of Pharmaceutical Manufacturing Drug Innovation in China}

For a long time, because of the weak related basic research in domestic medicine, most of the new drug research and development activities are limited to tracking and imitating the listed or patented drugs in development in Europe or America. At present, the generic way of domestic drug firms is narrower and narrower, it is becoming the key issue for the China's pharmaceutical industry survival and development to develop independent intellectual property rights and innovative drugs.

\subsection{The Main Part of Drug Development}

With the implementation of the strategy "building an innovative country" in China, the concept of "enterprise is the main body of technology innovation" has reached consensus. At present, the subject of engaging in the biological medicine research and development in China has become gradually by the national research institutes to CRO companies and pharmaceutical enterprises. National research institutes include state-owned institutions of higher learning, scientific research institutes and engineering technology center, etc. Such as Institute of Materia Medica, Chinese Academy of Medical Sciences, Shanghai Institute of Materia Medica, Chinese Academy of Sciences, Peking University School of Pharmaceutical Sciences, Shanghai Institute of 
Pharmaceutical Industry. The government provides a certain amount of money to support these institutes. In the country's long-term funding support, the institutes have established a drug innovation research and development team, mastered the key technology and accumulated the experience of achievements transformation, but the planning system also hindered the development and production of new drugs.

CRO (Contract Research Organization) is a contract research organization, it can provide kinds of technical services including early drug discovery, dosage form improvement, process optimization, economic evaluation and drug effect tracking, almost covering the whole process of new drug research and development. Chinese CRO industry has been growing rapidly since 2000, the market size in 2014 reached about 18.7 billion, accounting for more than $30 \%$ of the total global R\&D outsourcing market. The development of CRO industry in China will be conducive for pharmaceutical companies to learning the regularized operation and advanced experience of drug innovation in developed countries.

In recent years, domestic large pharmaceutical companies have been forming high level research and development institutions, increasing investment in research and development, and their innovation capability has enhanced markedly. From the data of listed pharmaceutical companies in China's pharmaceutical industry information center, we can see that the R\&D investment in listed pharmaceutical companies in 2013 reached 12.3 billion yuan, accounting for $29 \%$ of the net profit. In recent years, some overseas scientific research personnel has returned to their motherland and introduced the foreign advanced research and development mode to domestic companies, this produced some pharmaceutical enterprises which are leaded by returnees team, such as Shenzhen Chipscreen, Zhejiang Conmana, Yantai Medgenn Co., Ltd.

\subsection{The Drug R\&D Investment}

As shown in China statistics yearbook on high technology industry, the R\&D investment in biological pharmaceutical industry is 25.89 billion yuan in China in 2013, it has become second after the electron and communication equipment industry. And the intensity is $1.99 \%$ which is higher than the average level of high technology industry $1.89 \%$ (Figure 1).

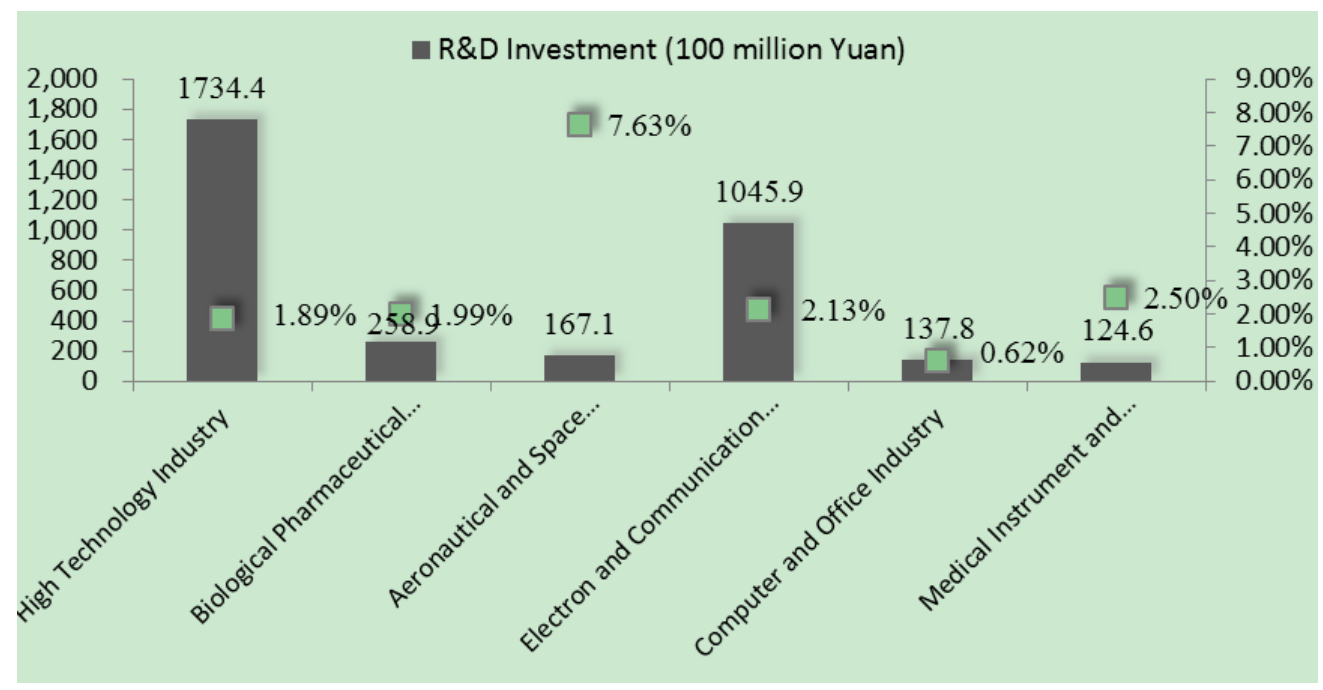

Figure 1. R\&D Investment in Chinese large and medium-sized industrial enterprises in 2013

Source: China statistics yearbook on high technology industry

In the biological medicine industry, the R\&D investment of chemical manufacturing industry is highest, and accounts for about $60 \%$ of the total R\&D investment of biological medicine high-tech enterprises. The proprietary Chinese medicine sector accounts for about $20 \%$, and the biological/chemical products manufacturing sector accounts for about $12.7 \%$ (Table 1). From the developing trend of recent five years, the $\mathrm{R} \& \mathrm{D}$ investment of biological medicine high-tech enterprises is growing rapidly, the average annual growth rate is $45 \%$, which is higher than the average level of China's high technology industry $33 \%$. The R\&D investment of biological and biochemical products manufacturing sector is growing most rapidly in biomedical field. 
Table 1. The R\&D investment of China biological medicine high-tech enterprises in 2008-2013 (100 million yuan)

\begin{tabular}{lllllll}
\hline & 2008 & 2009 & 2010 & 2011 & 2012 & 2013 \\
\hline biological medicine industry & 79.1 & 99.6 & 122.6 & 156.3 & 214.9 & 258.9 \\
chemical manufacturing industry & 52.1 & 63.6 & 81.4 & 100.3 & 129.8 & 153.3 \\
proprietary Chinese medicine sector & 16.3 & 20.4 & 20.8 & 25.6 & 39.2 & 51.8 \\
biological/chemical products manufacturing sector & 6.7 & 9.7 & 13.3 & 17.4 & 28.3 & 33.0 \\
high technology industry & 655.2 & 774.0 & 967.8 & 1237.8 & 1491.5 & 1734.4 \\
\hline
\end{tabular}

Source: China statistics yearbook on high technology industry

\subsection{The R\&D Situation of Independent Innovative Drug in China}

From the new drug registration situation, we can see that the domestic original drugs application for registration accepted by the Center for Drug Evaluation (CDE) is increasing year by year, it expanded significantly from the number of companies involved in innovative drug research and development, the number of drug varieties to the drug indication range. Take Chemical medicine as an example, the new drug number of 1.1 class accepted by CDE increased to 74 in 2013 from 27 in 2009, the declaration enterprise number increased to 62 in 2013 from 30 in 2009. The R\&D situation of Biotech drugs has a similar trend (Table 2).

Table 2. The application situation of China's independent innovative medicine in 2009-2013

\begin{tabular}{lllllll}
\hline & & 2009 & 2010 & 2011 & 2012 & 2013 \\
\hline $\begin{array}{l}\text { Chemical } \\
\text { medicine }\end{array}$ & $\begin{array}{l}\text { The new drug number of 1.1 class (According to } \\
\text { the common name) }\end{array}$ & 27 & 33 & 45 & 47 & 74 \\
& The declaration enterprise number & 30 & 30 & 39 & 42 & 62 \\
\hline \multirow{5}{*}{ Biotech drugs } & The new drug number of 1 class & 7 & 14 & 15 & 22 & 32 \\
& The new drug number of 2 class & 1 & 3 & 3 & 4 & 9 \\
& The new drug number of 3 class & 1 & 1 & 2 & 2 & 3 \\
& The total of declaration enterprise number & 9 & 17 & 22 & 29 & 42 \\
\hline
\end{tabular}

Source: The Center for Drug Evaluation (CDE)

Note: According to classification of new drug registration regulation in the drug registration management measures (2005 edition), 1.1 class new medicine of chemical medicine refers to the never listed chemical drugs at home and abroad through the synthetic or semi synthetic method. 1 class new drug of biological products refers to the never sold therapeutic biologics or vaccine in domestic and foreign market, 2 class new drug refers to the monoclonal antibody or DNA vaccines, 3 class new drug refers to gene therapy, cell therapy and its products, or the new adjuvants changed from the selling vaccine, the new carrier changed from coupling vaccine.

\section{The Problems of Chinese Government's Drug Innovation Incentive Strategy}

It is short of a whole for the Chinese government to control the compensation standard, evaluation, pricing and regulatory scrutiny of innovative drugs. It is mainly manifested in the following aspects, the government didn't do scientific and reasonable evaluation of drug innovation for pricing, and innovative drugs is difficult to be listed by the medical insurance directory.

\subsection{Overall Lack of Innovative Drug Control}

China's current drug price control system is short of effective control of innovative drug prices. According to the relevant provisions, innovative drugs are priced independently by the enterprise before it is listed in the catalog of medical insurance drugs or the catalog of national essential drugs. Because of information asymmetry in the medical market and vital thing, the high price fixed by enterprises in order to obtain the maximum interest can be more easily passed on to patients by influencing the doctor prescription behavior. Therefore, there was a spectacle that thousands of kinds of new drugs come into the market a year in China before the new edition of 
drug registration management approach is issued. The phenomenon is closely related to the independent pricing power of new registered drug.

Although some of the new registered drugs appeared on the market have obvious curative effect, or have obvious advantages on the safety and good quality level, more of the drugs are the replacement for the original drugs by changing production packing, specifications, capacity and so on, the new drugs do not have effective innovative. Many new registered drugs' prices do not match with their qualities, this not only increases the burden of patients, but also brought new challenges for the management of drug prices. Otherwise, many drug makers keep on doing combination and adjustment in the specifications, packing and capacity of their produced drugs to obtain new drug registration because of the lack of scientific pricing standard in China. This not only isn't conducive to the healthy development of the pharmaceutical market, but also can't make full use of the effective resources.

Therefore, the current Chinese government is overall short of control of standard, the evaluation, price compensation and regulatory scrutiny of innovative drugs. As a result, on the one hand, some really necessary innovative drugs for clinical treatment is excluded outside compensation directory, this causes a heavy economic burden for patients and damages to citizens' health and welfare. On the other hand, in Domestic drug on the market the low level new registered drug is flooded and overall level of prices is artificially high, this is unable to realize real incentives for the enterprises' innovation.

\subsection{It Is Difficult for Innovative Drugs to Enter into the Medical Insurance Directory}

The Chinese medical insurance directory in the management has the mode of "emphasizing steadiness, despising level and expanding coverage". The conditions of clinical need, safe and effective, reasonable price, easy use, and keeping supply has been set up on the medical insurance directory selection mechanism, and expert review is needed, the process of medical insurance directory update time is $4-5$ years. Therefore a lot of domestic new drugs with good curative effect and lower price than the similar imported drugs could not been listed in medical insurance directory, this damaged the enthusiasm of enterprise technology innovation. The IMS Health company published a study of innovative drug procurement and access in China in 2013, according to the study, the average time for patients getting new reimbursable drug in China is 8 years later than other countries, because there are a large of new innovative drugs with lagging bidding, registration and reimbursement. As shown in China's pharmaceutical industry information center data, $30 \%$ of the new launched drugs still failed to enter into any province medical insurance directory after two years later in the past five years. At the same time, the provincial government can supplement the non-directory classes, and can change the directory with $15 \%$, this seriously affected the enterprise drug innovation enthusiasm. Therefore, along with China's urbanization, industrialization and faster aging, it is dual requirements of guaranteeing people's rational drug use and encouraging innovation to index the cost-effective new drugs into the medical insurance directory in time.

In 2009, the state council explicitly put forward in "about the opinions of the deepening medical and health system reform" that "actively explore establishing the negotiation mechanism among agency of medical treatment insurance, medical institutions and drug supplier, exert effectiveness of health care on the costs of medical services and drugs". Human resources and social security ministry proposed negotiation mechanism of medical treatment insurance in "the work plan of medical insurance directory adjustment" for the first time in 2009. This shows that China's medical insurance management thinking is entering the negotiation model from the original standards of "low level, wide coverage, sustainable" and meeting the basic medical needs, this provides the possibility for the cost slightly higher innovative medicine through negotiation mechanism to enter the medical insurance directory. In 2013, the negotiation model of exploration, the periodic progress, Ministry of Human Resources and Social Security of Jiangsu Province established the measures for the implementation of special drug administration of medical treatment insurance, Herceptin in Roche pharmaceuticals for the treatment of breast cancer (Trastuzumab for injection) become the first landing drugs of the system. So far, the process of innovative medicines through negotiation mechanism into the medical insurance directory is still in the case.

\subsection{The Legal System of Government Pricing Regulation Is Not Sane}

Innovative drugs' quality or curative effect is superior to the ordinary drugs, the high price must be based on its better curative effect and safety compared with commercially available medicine, this is the root cause of its high price. If we want to incorporate innovative drug pricing into regulating scope, the judgement of its innovation is particularly important. At present, the system standard is very short for China's drug regulators to evaluate the innovative drug pricing. Generally speaking, it is closed related to innovative drug approval conditions whether the innovative drug approval process is scientific and whether the price review process is in accordance with the relevant provisions. At present, the approval process of China's innovative drugs is short of systematic 
examination and approval rules, this results that there are many interference factors in the process of innovative medicine' examination, approval and pricing and drug innovation work could not been effectively guided as well.

A key problem that the governments around the world meet when they draw up the prices and compensation system of innovative drugs is whether the evaluation system is scientific and reasonable. For example, the French experience is worthy of reference for the Chinese government. French governments first classify pharmaceutical active ingredients to determine the degree of new drug innovation.

\section{The Analysis of Drug Pricing Compensation Policy's Incentive Mechanism for Innovation}

Drug pricing compensation policy is always a hot spot in the industry. Given the drug prices are artificially high and the order of medicine market is confusing, Chinese government took two important actions in drug pricing compensation policy, one is the adjustment of highest government management retail price, the other is the adjustment of national health care medicine catalogue in 2009.

\subsection{The Drug Pricing Policy}

In principle, China's national development and reform commission adjust drug prices within the government pricing scope once every two years. Since 1997, the national development and reform commission has adjusted the highest drug retail price in the government pricing catalog more than 30 times, the highest retail price cut becomes the absolute main melody. For example, the adjustment in China's national development and reform commission file in February 2013 (Development and reform price [2012] no. 4134) involved 20 kinds of drugs, the varieties are more than four hundred and the dosage forms are more than seven hundred. The overall price of these drugs was lowered, the size of the cut was $15 \%$. What we need to know is that this price adjustment activity not only cut drug prices, but also implemented certain price support policy for low-cost drugs. In order to encourage some low price drug makers' enthusiasm of producing drugs, China's national development and reform commission raised the market price of drugs to some extent after a large number of investigation and analysis and summarizing all the opinions of the expert team.

The cut of drugs of the highest retail price is helpful for patients to reduce their economic burden, and is widely welcomed by the society, but this may also bring great effect on normal operation of innovative drugs and sustainable development of enterprise. On this account, it is a double-edged sword for innovative medicine to enter into the health care medicine directory, for one thing, the consumer crowd of the listed drugs may increase rapidly, product sales are expected to increase. For another, the listed drugs must accept the highest retail price management by government and the control of hospital medical insurance amount, this will affect the enterprises recovering the cost of innovative drugs as soon as possible.

\subsection{The Drug Compensation Policy}

For innovative medicines, it directly affects the market incentives of innovative drugs where they could get the qualifications of compensation and the difficulty of getting compensation. Compared with the 2004 version of the medical insurance directory, there are 460 new drugs brought in (including 226 western drugs and 234 Chinese drugs) and 128 drugs removed in the 2009 edition of the national basic medical treatment, industrial injury and birth insurance drug catalogue, the adjusted proportion is nearly a quarter. In the 226 western drugs (According to the common name), the drugs coming into the market for more than five years (The drugs approved 2004 years ago) accounted for $44.2 \%$, the domestic varieties issued after the 2004 version of the health care medicine directory was published accounted for a third, the varieties depending on import accounted for about $1 / 5$. According to the data, the lag of Chinese medical insurance directory update is outstanding relative to the drug innovation (Figure 2). 


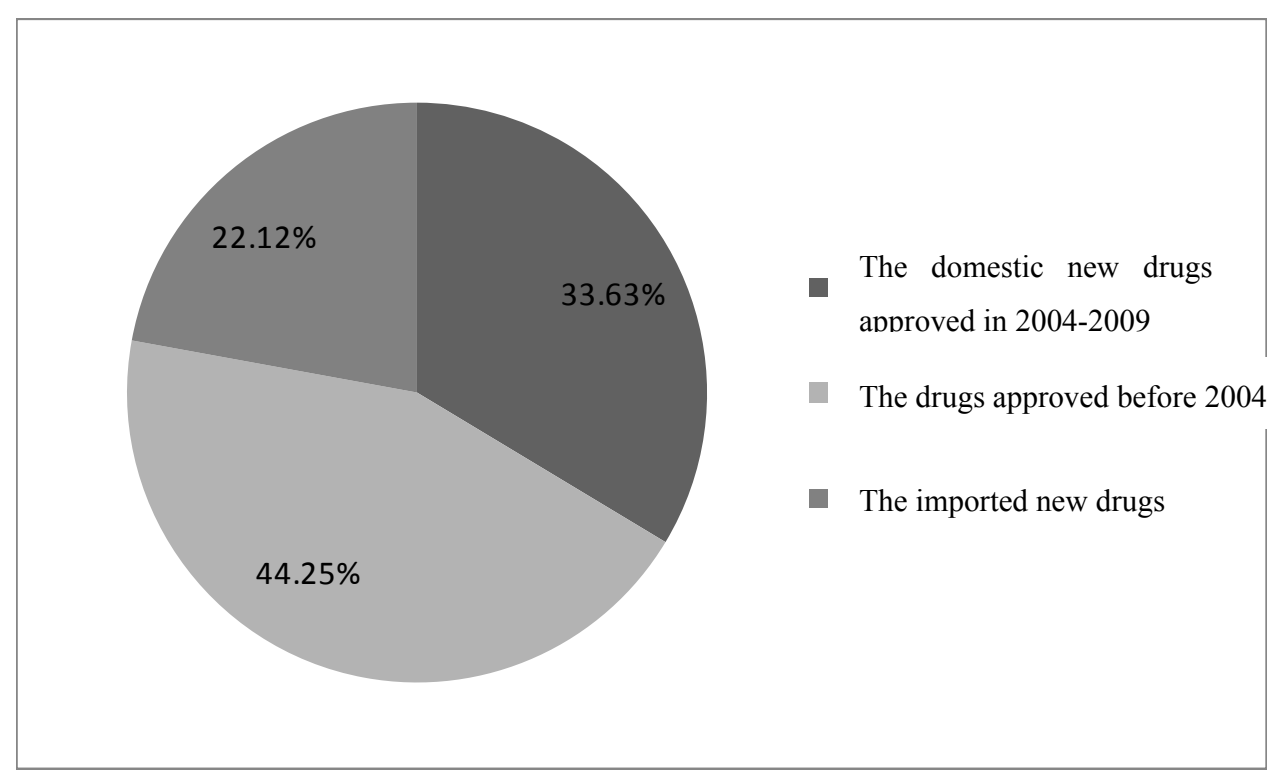

Figure 2. The innovation of new drugs in 2009 medicare catalog

By the drug registration information retrieval in China Food and Drug Administration (CFDA), 23 new drugs registered classified as A were approved in the adjustment period of 2009 health care medicine directory (2005-2009) in the field of Chinese medicine. 15 kinds of the 23 new drugs were listed in the 2009 health care medicine directory, that is to say, the rate of domestic A new drugs included in the new medical insurance directory is $65.2 \%$ in the adjustment period. Obviously, China's drug compensation policy support had a certain policy tilt for the original high drug innovation achievements.

\subsection{The Market Performance of Innovative Drugs}

Due to the weak ability of Chinese medicine industry drug discovery, most innovative drugs in the domestic drug market were from the multinational pharmaceutical enterprises' imported drugs. If the multinational company imported drugs in the market and the listed domestic drugs after 2005 are defined as "innovative medicine", according to the medicine purchase data of more than 400 hospitals (Note 1) in first-tier and second-tier cities in China in 2013, the sales income of "innovative medicine" accounted for $25.6 \%$ of total sales income, the compound growth rate is $36.3 \%$ in the period of 2005-2013 (Figure 3), while the year compound growth rate of listed drug sales is only $15.9 \%$ in the same period before 2005 . We can know that the innovative drug is the main power to promote the growth of pharmaceutical market. 


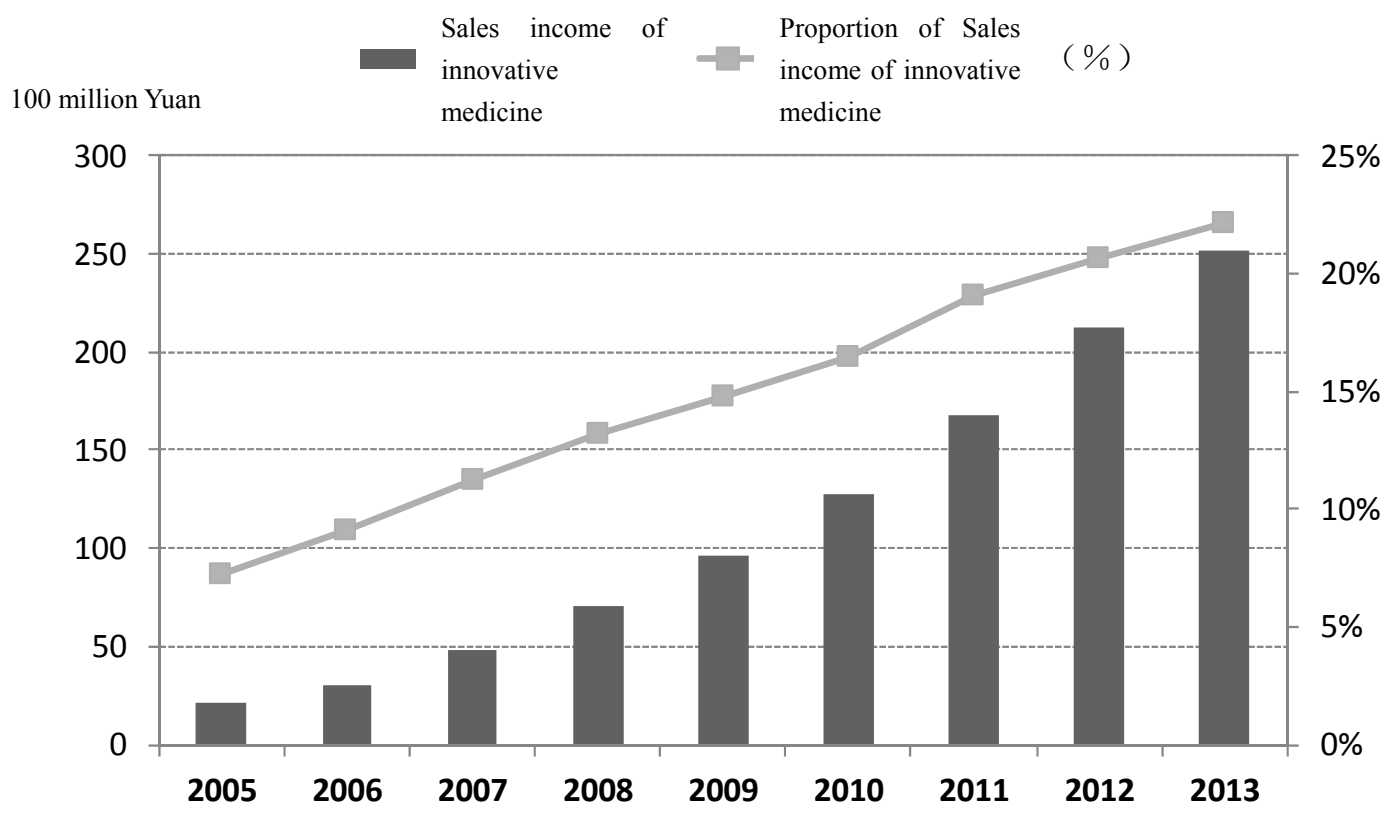

Figure 3. The innovative medicine sales income and its proportion of sample domestic hospitals (2005-2013)

Data sources: China's pharmaceutical industry information center

The data also shows that the sales income proportion of medical insurance drugs in innovative drugs is about $50 \%$, but lower than the proportion of medical insurance drugs in overall drug sales (67\%-70\%). Thus, drug compensation policy fails to provide enough support for innovative medicines, the market growth of innovative drug depends on the growth of private spending more. As a result of the slow update cycle of China's health care medicine directory, and having no relevance with the situation of listed innovative drugs, the market share of medical insurance drugs in innovative drugs shows a trend of gradual decline until the medical insurance directory is update (Figure 4). 


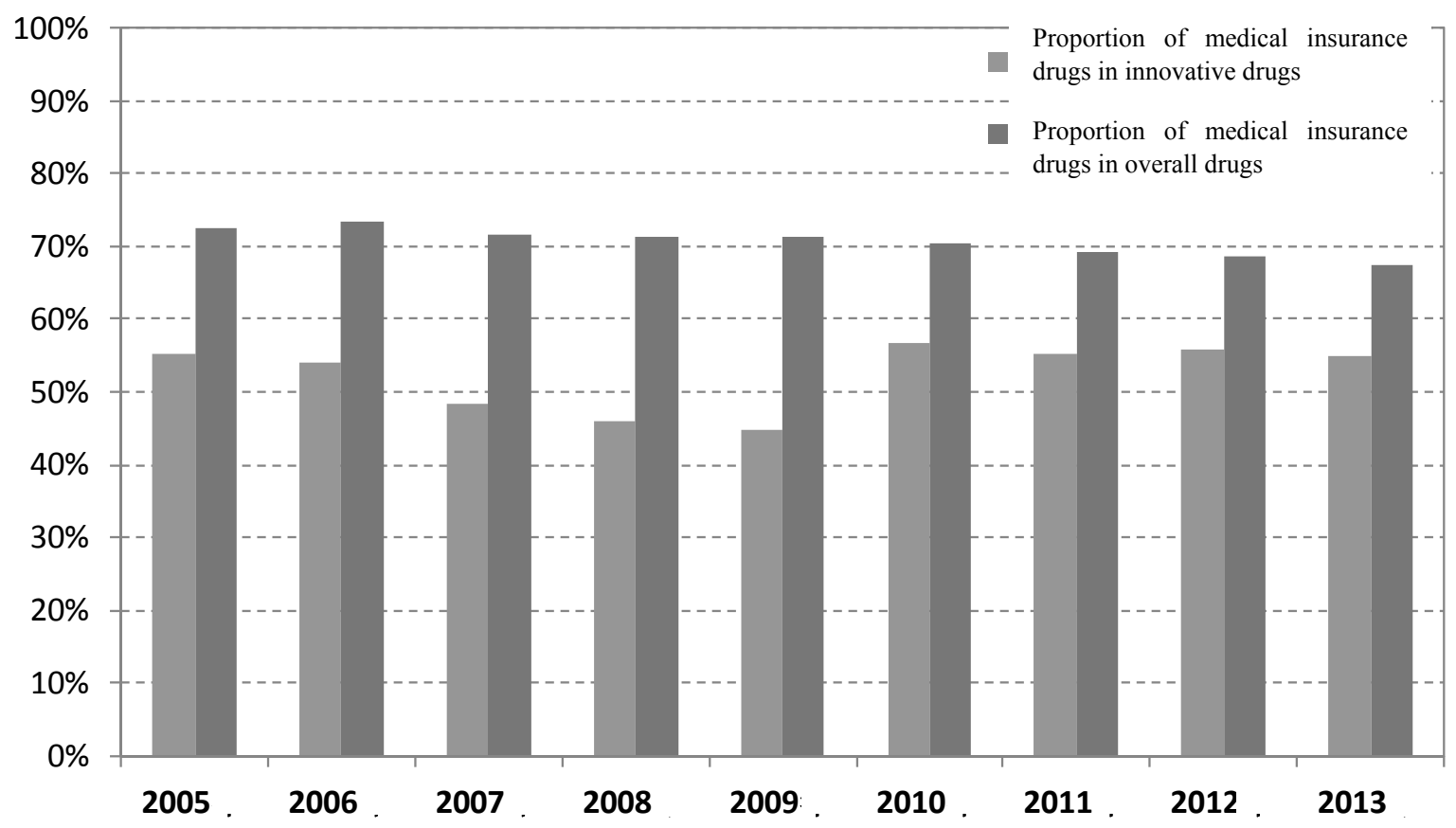

Figure 4. The relative weight of medical insurance drugs in innovative drugs in samples of domestic hospitals Data sources: China's pharmaceutical industry information center

Forming the above situation is related to and Chinese medicine research and development system and marketing ability. For a long time, China's scientific research activities mainly focus on scientific research institutes, the research and development expense is mainly borne by the government. Therefore, the R\&D expense always has no direct and inevitable connection with the innovation project success and the market demand, the result must be the disconnection between developed and the market. In addition, the professional marketing ability is insufficient before and after the product comes into the market is also an important influencing factor conducing to the weakness of the market competitiveness of China's independent innovation drugs.

\section{The Government Adopts the Innovation Incentive Strategy of Controlling Drug Price}

Against the problems which the Chinese government exists in the drug innovation incentive process, the government need play the role of macro adjustment to control price, such as establishing drug economics evaluation system, reducing the barriers for innovative drugs to enter the compensation directory and using the price negotiation mechanism.

\subsection{Set up a Scientific System of Pharmacoeconomics Evaluation}

On innovative drug supervision, the intervention which many countries take is positively support through policy to provide a good external environment for the clinical use of innovative drugs. As the world's largest developing country, China should actively learn from the international pharmaceutical pricing strategy to standardize the order of innovative drugs market.

In the past 20 years, the rapid growth of the medical expense is a problem that both the developed countries and developing countries are facing. When the drugs are priced via drug economics, the drug clinical value must be considered to encourage enterprises to research and development the production with high clinical value. For example, in the pricing management of innovative medicines, some main countries in the world introduce inordinately many indicators, such as the clinical benefit, originality, economy of innovative drugs, as the basis of pricing. In France, the clinical effectiveness level and the improved degree of clinical benefit must be evaluated before the innovation drug is priced and determined into the medical insurance directory. Taking distinguishing pricing policies for different types of new drugs via the pharmacoeconomics evaluation system can enhance the management policy of innovative medicines and prompt new pricing policy to be in line with the drugs in innovation degree. 


\subsection{Reduce the Barriers for Innovative Drugs to Enter the Compensation Directory}

The improvement of the medical insurance directory is connected with the implementation of masses' health and welfare, and is also closed related to the realization of pharmacy industries' long-term effective development. In view of this, the effective improvement of medical insurance directory needs people from all walks of life work together and provide conditions for innovative drugs to enter the compensation directory in the aspects of system, policy and degree in order to achieve the effective development of the domestic pharmaceutical industry.

At present, China's medical insurance directory drug selection still follows the principle of "low level, wide coverage, sustainable" and meeting the basic medical needs, the interval time of medical insurance directory updating is 4-5 years, with the result that many good curative effect, high safety and lower price domestic new drugs are unable to enter medical insurance directory. Therefore, the relevant government departments should start to improve the access conditions of medical insurance drugs directory to provide conditions for new drugs to enter the medical insurance directory. The suggestions of scientific research personnel should be considered and adopted in the work of medical insurance drugs directory's improvement. For example, the departments of Shanghai medical insurance bureau, Shanghai municipal development \& reform commission and Shanghai science and technology commission establish the cooperation relations to make new drugs of local enterprises enter into the medical insurance directory through the power of parties.

\subsection{Try to Innovate the Mechanism of Drug Price Negotiations}

It will inevitably increase the payment risk faced by medical insurance fund to make the expensive innovative drugs into medicare reimbursements directory. The experience from developed countries has shown that it may be a win-win choice to include the drug price negotiation mechanism in the process of directory adjustment. Firstly, it will help manufacturers improve their drug's share of the market to achieve a good drug marketing. Secondly, it can reduce the drug consumption personal expenses of patients. Thirdly, it can reduce the idle medical insurance fund. From the international experience, innovative drug price negotiations can be divided into three categories. One is drawing up price sales agreement, namely the quantity and price "hook" group purchasing mode. The second category is conditional compensation agreement based on the performance, that is the mode of sharing drug cost between government and pharmaceutical factory according to the effect of clinical treatment. The third category is the agreement formulated on the basis of the financial risk and the mode of sharing drug cost according to financial index, such as the mode of fixing the total payment or capitation payment. At present, Chinese provinces are actively exploring innovative drug price negotiation mechanism. For example, Icotinib Hydrochloride Tablets (lung cancer targeted therapy drug) produced by Zhejiang Beta Pharma has successfully entered the medicare reimbursement directory of Qingdao and Zhejiang province through negotiation.

\subsection{Use Various Mechanisms of Controlling Medical Costs}

There are many factors causing the rise of medical expense, such as the objective factors including the affect of population aging, the increased cost of new drug development, and the unreasonable subjective factors including too much medicine circulation link, the misleading medical treatment. To maintain the healthy development of the pharmaceutical industry and balance of medical insurance fund payments, comprehensive use of various control mechanisms are need to ensure that listed drug price is reasonable and avoid excessive use of health costs. For example, for the drug pricing and health cost control, the French government adjust prices of drugs which did not reach a certain standard for clinical value in order to ensure that the drugs' adjusted prices are consistent with their utilities, based on the evaluation report issued by transparent committee once every four years. The French government carries out the improvement and adjustment of the two items related to medical insurance drugs directory and the compensation ratio according to the results of evaluation, and adjust floating reimbursement ratio according to the balance of annual fund payments situation through the national health insurance fund alliance (UNCAM). However, China is still short of such integrated control mechanism of medical expenses in drug price management.

\section{Conclusion}

Drug innovation is an important symbol of national pharmaceutical industry development level, and is the main power to promote the development of pharmaceutical economy. China's drug innovation incentive exists many problems, such as the overall vacancy of innovation controls, difficulty of entering the directory of medical treatment insurance and the imperfection of legal system of drug price regulation. With the implementation of the strategy of "innovative country", Chinese government strengthened the support to new drug development, and the research and development direction has been given priority to combination of innovation and imitation from imitation gradually. Drug pricing compensation mechanism drives the innovation activities of 
pharmaceutical manufacturing industry, but the current drug compensation policy fails to provide enough support for innovative medicines, the market growth of innovative drugs more depends on the growth of private spending. Therefore, the government should play the role of incenting drug innovation via price, such as setting up a scientific system of pharmacoeconomics evaluation, reducing the barriers for innovative drugs to enter the compensation directory, trying to innovate the mechanism of drug price negotiations, using various mechanisms of controlling medical costs.

\section{References}

Center for Drug Reevaluation (CFDA). (2014). 2013 China Drug Review Annual Report. Retrieved February 28, 2014, from http:/www.sda.gov.cn/WS01/CL0051/97314.html

Claxton, K., \& Sculpher, M. J. (2006). Using value of information analysis to prioritise health research: some lessons from recent UK experience. Pharmacoeconomics, 24, 1055-1068. http://dx.doi.org/10.2165/00019053-200624110-00003

Danzon, P. M., \& Chao, L. (2000). Does Regulation Drive out Competition in Pharmaceutical Markets? Journal of Law and Economics, 43(2), 311-357. http://dx.doi.org/10.1086/467458

Fan, M. X. et al. (2010). Study on the Competitive Advantage of Contract Research Organizations in China. Forum on Science and Technology in China, (5), 36-40.

Giaccotto, C., Santerre, R. E., \& Vernon, J. A. (2005). Drug prices and research and development investment behavior in the pharmaceutical industry. J Law Econ., 48, 195-214. http://dx.doi.org/10.1086/426882

Green, C. (2010). Considering the value associated with innovation in health technology appraisal decisions (deliberations): A NICE thing to do? Appl Health Econ Health Policy, (8), 1-5. http://dx.doi.org/10.1007/BF03256161

$\mathrm{Hu}, \mathrm{S}$. L. et al. (2003). International experiences of drug reimbursement based on different categories. Health economics research, (6), 17-19.

Leader. (2007, February 21). In search of a perfect price for drugs. Financial Times.

Lu, Z. L. (2012, August 13). IMS medicine market research: It is eight years behind internation to get new reimbursable drugs in China. Yangcheng Evening, p. A16.

Ministry of Human Resources and Social Security of People's Republic of China. (1999). The interim measures of urban employee' basic medical insurance scope management. Retrieved February 28, 2014 from http://www.molss.gov.cn/gb/ywzn/2006-02/14/content_106436.htm

Tang, S. L., Tao, J. J., \& Bekedam, H. (2012). Controlling cost escalation of healthcare: making universal health coverage sustainable in China. BMC Public Health, 12(Suppl 1). Retrieved February 28, 2014, from http://www.ncbi.nlm.nih.gov/pubmed/22992484

Yan, J. (2012). Formulation of Typical National Drug List and its Enlightenment of China. Chinese hospital management, 32(9), 58-60.

\section{Notes}

Note 1. China's pharmaceutical industry information center PDB database, sample hospitals were representative comprehensive and specialized subject hospitals selected from 46 cities in 21 provinces/municipalities directly under the central government (above 100 beds).

\section{Copyrights}

Copyright for this article is retained by the author(s), with first publication rights granted to the journal.

This is an open-access article distributed under the terms and conditions of the Creative Commons Attribution license (http://creativecommons.org/licenses/by/3.0/). 